\title{
Genome-Wide Identification of Genes Regulated by the Rcs Phosphorelay System in Erwinia amylovora
}

\author{
Dongping Wang, ${ }^{1}$ Mingsheng Qi, ${ }^{1}$ Bernarda Calla, ${ }^{1}$ Schuyler S. Korban, ${ }^{2}$ Steven J. Clough, ${ }^{1,3}$ \\ Peter J. A. Cock, ${ }^{4}$ George W. Sundin, ${ }^{5}$ lan Toth, ${ }^{4}$ and Youfu Zhao ${ }^{1}$ \\ ${ }^{1}$ Department of Crop Sciences, ${ }^{2}$ Department of Natural Resources and Environmental Sciences University of Illinois at \\ Urbana-Champaign, Urbana, IL 61801, U.S.A.; ${ }^{3}$ USDA Agricultural Research Service, Urbana, IL 61801, U.S.A.; ${ }^{4}$ Cellular \\ and Molecular Sciences, The James Hutton Institute, Invergowrie, Dundee DD2 5DA, U. K.; ${ }^{5}$ Department of Plant Pathology, \\ Michigan State University, East Lansing, MI 48824, U.S.A.
}

Submitted 5 August 2011. Accepted 14 September 2011.

\begin{abstract}
The exopolysaccharide amylovoran is one of the major pathogenicity factors in Erwinia amylovora, the causal agent of fire blight of apples and pears. We have previously demonstrated that the ResBCD phosphorelay system is essential for virulence by controlling amylovoran biosynthesis. We have also found that the hybrid sensor kinase ResC differentially regulates amylovoran production in vitro and in vivo. To further understand how the Res system regulates $E$. amylovora virulence gene expression, we conducted genome-wide microarray analyses to determine the regulons of $\operatorname{Rcs} B$ and $\operatorname{Res} C$ in liquid medium and on immature pear fruit. Array analyses identified a total of 648 genes differentially regulated by $R \operatorname{csCB}$ in vitro and in vivo. Consistent with our previous findings, $R \operatorname{csB}$ acts as a positive regulator in both conditions, while $\mathrm{Res} C$ positively controls expression of amylovoran biosynthetic genes in vivo but negatively controls expression in vitro. Besides amylovoran biosynthesis and regulatory genes, cell-wall and cell-envelope (membrane) as well as regulatory genes were identified as the major components of the RcsBC regulon, including many novel genes. We have also demonstrated that transcripts of $r c s A, r c s C$, and $r c s D$ genes but not the $\operatorname{rcs} B$ gene were up-regulated when bacterial cells were grown in minimal medium or following infection of pear fruits compared with those grown in Luria Bertani medium. Furthermore, using the genome of $E$. amylovora ATCC 49946, a hidden Markov model predicted 60 genes with a candidate RcsB binding site in the intergenic region, 28 of which were identified in the microarray assay. Based on these findings as well as previous reported data, a working model has been proposed to illustrate how the Res phosphorelay system regulates virulence gene expression in E. amylovora.
\end{abstract}

Erwinia amylovora, the causal agent of fire blight disease, is one of the most important bacterial plant pathogens causing significant economic losses around the globe (Vanneste 2000). Production of the exopolysaccharide amylovoran as one of the main pathogenicity factors is a unique characteristic of this bacterium that is exhibited as ooze on infected tissues (Bugert

Corresponding author: Y. Zhao: E-mail: zhao888@illinois.edu; Telephone: 1-217-265-9822; Fax: 1-217-333-4582.

* The $e$-Xtra logo stands for "electronic extra" and indicates that three supplementary tables and one supplementary figure are published online. and Geider 1995; Zhao et al. 2005, 2006). Amylovoran is a large heteropolymer composed of a repeating unit consisting of galactose, glucose, and pyruvate residues (Nimtz et al. 1996). Genes involved in amylovoran biosynthesis and secretion are located on a 16-kb genomic island (Bugert and Geider 1995). The 12 amylovoran biosynthetic genes amsG to amsL are transcribed as a single amylovoran biosynthesis (ams) operon and are driven by the promoter of the first gene ams $G$ (Bernhard et al. 1993). Mutations of amylovoran biosynthetic genes result in abolished amylovoran production and render the bacterium nonpathogenic on host plants (Bellemann and Geider 1992; Kelm et al. 1997; Wang et al. 2009; Zhao et al. 2009b). Previous studies have implicated multiple functions for amylovoran in Erwinia pathogenesis, including blocking plant vascular tissues, assisting movement of the bacteria through cortical tissue, stress resistance, and in biofilm formation (Khan et al. 2011; Koczan et al. 2009; Sjulin and Beer 1978).

The two-component signal transduction (TCST) systems represent paradigms for gene regulation in prokaryotes (Hoch and Silhavy 1995; Kato et al. 2007). Our comprehensive work has revealed that TCST systems in E. amylovora may form a network that governs the production of amylovoran (Zhao et al. 2009b). Among the TCST systems, the RcsCDB phosphorelay system positively regulates amylovoran production and is essential for virulence (Wang et al. 2009). Knockout $r \operatorname{cs} B$ and $r c s D$ mutants are deficient in amylovoran production in vitro and cannot cause disease on host plants. Although the $r \operatorname{cs} C$ mutant produces high levels of amylovoran in vitro, it remains nonpathogenic. Further comparative analyses indicate that the sensor domain of RcsC may be important in regulating bacterial virulence; whereas, the activity of the histidine kinase and receiver domains of Erwinia $\mathrm{RcsC}$ may be essential in controlling amylovoran production in vitro, suggesting that an unknown specific in vivo signal may be sensed by RcsC, which is absent in vitro (Wang et al. 2011).

The Rcs phosphorelay system, a complex atypical TCST system, is composed of three proteins, including RcsC, RcsD, and RcsB, and involves several auxiliary proteins such as RcsA, which are required for normal function (Clarke 2010; Huang et al. 2006; Majdalani and Gottesman 2005). However, the core of the Rcs system is the response regulator RcsB and the membrane-localized hybrid sensor kinase $\mathrm{RcsC}$, which represent the classical members of bacterial TCST systems. The third member, RcsD, is also a membrane-bound sensor and is believed to form a complex with RcsC and RcsB through a new $\alpha-\beta$-loop (ABL) domain found in both RcsC 
and RcsD (Schmoe et al. 2011). However, RcsD appears to be inactive, as it lacks conserved residues in the active sites. The auxiliary protein RcsA, an unstable cytoplasmic protein, is similar to RcsB but without the conserved aspartate residue in its N-terminal receiver domain (Bernhard et al. 1990; Carlier and von Bodman 2006). RcsA interacts with phosphorylated RcsB to form a heterodimer that binds to promoters of Rcsregulated genes, including the promoter of the ams operon that is involved in amylovoran biosynthesis (Pristovsek et al. 2003).

The signal transduction mechanism of the Rcs system is an unusual multiple step phosphorelay, i. e., His-Asp-His-Asp, and the state of phosphorylation of Rcs proteins modulates their interaction (Clarke 2010; Huang et al. 2006; Majdalani and Gottesman 2005). It is generally accepted that, upon sensing correct environmental stimulus or stimuli, the sensor kinase RcsC autophosphorylates a conserved histidine residue in its histidine kinase domain. The phosphoryl group is then transferred to an aspartate residue in the receiver domain of $\mathrm{RcsC}$ on the C-terminal and is further transmitted to the $\mathrm{N}$-terminal phosphoreceiver domain of $\mathrm{RcsB}$ via a unique C-terminal histidine-containing phosphotransmitter domain of RcsD. The phosphorylated RcsB can either form RcsBRcsB homodimers or interact with RcsA to form RcsAB heterodimers, which then bind to an "RcsAB box" (TaAGaatat TCctA) to regulate gene expression (Wehland and Berngard 2000; Wehland et al. 1999). However, the exact signal or signals for RcsC remain unclear, especially under in vivo conditions. Moreover, the regulation of the Rcs system itself and the number of target genes regulated in vivo by the Rcs system remain largely unknown.

The goal of this study was to better understand why mutation of the $r c s C$ gene in E. amylovora leads to overproduction of amylovoran in vitro while the mutant remains nonpathogenic in vivo and to further identify regulons of RcsB and $\mathrm{RcsC}$ of E. amylovora, both in vivo and in vitro. Genome-wide gene expression experiments were performed by comparing wild type (WT) and mutant bacterial strains that were either grown in minimal medium or inoculated onto surfaces of immature pear fruit. This study expands on the current knowledge about how the Rcs system regulates gene expression, especially in vivo, which has yet to be described in any other bacterial systems. Based on our findings, a working model has been proposed to illustrate the regulation of virulence factors in E. amylovora via the Rcs system.

\section{RESULTS}

Genes differentially expressed in $r \operatorname{cs} B$ and $r \operatorname{cs} C$ mutants.

In order to identify the RcsBC regulon, microarray analyses were conducted to compare gene expression in the $\operatorname{rcs} C$ or $r \operatorname{cs} B$ mutants with those of the WT strain Ea1189 on pear fruits

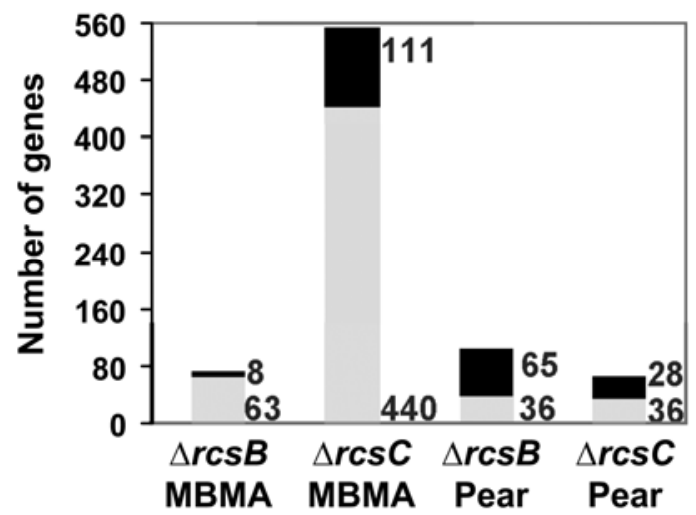

Fig. 1. Number of differentially expressed genes in $r c s B C$ mutants compared with the wild-type strain. Differential expressed genes are those exhibiting over twofold change and a $P$ value $<0.05$. Black columns represent genes expressed at higher levels, and gray columns represent genes expressed at lower levels in $r \operatorname{cs} B$ or $r \operatorname{cs} C$ mutants. The numbers adjacent to the columns represent the numbers of genes in each condition.

Table 1. Expression ratio of $r c s, a m s$ and other novel genes in $r c s B$ and $r c s C$ mutants compared with wild-type (WT) strain ${ }^{\text {a }}$

\begin{tabular}{|c|c|c|c|c|c|c|}
\hline Gene ID & Gene & $\begin{array}{c}\Delta r c s C / W T \\
\text { Pear }\end{array}$ & $\begin{array}{c}\Delta r c s B / W T \\
\text { Pear }\end{array}$ & $\begin{array}{c}\Delta r c s C / W T \\
\text { MBMA }^{\mathbf{b}}\end{array}$ & $\begin{array}{c}\Delta r \operatorname{cs} B / W T \\
\text { MBMA }^{\mathbf{b}}\end{array}$ & Protein description \\
\hline EAM_1482 & $\operatorname{rcs} A$ & 0.24 & 0.05 & 2.0 & 0.02 & Amylovoran biosynthesis activation protein A \\
\hline$E A M \_2262$ & $r \operatorname{cs} B$ & $1.25^{\mathrm{c}}$ & 0.0002 & $1.05^{\mathrm{c}}$ & 0.0009 & Two-component response regulator \\
\hline$E A M \_2263$ & $\operatorname{rcs} C$ & 0.005 & $0.67^{\mathrm{c}}$ & 0.05 & $0.61^{\mathrm{c}}$ & Two-component system, sensor kinase \\
\hline EAM_2261 & $r c s D$ & 0.75 & 0.56 & 0.89 & 0.51 & Two-component system, kinase \\
\hline$E A M \_2171$ & amsA & 0.23 & 0.19 & 2.9 & 0.25 & Amylovoran biosynthesis tyrosine-protein kinase \\
\hline$E A M \_2170$ & $a m s B$ & 0.26 & 0.21 & 2.9 & 0.33 & Amylovoran biosynthesis glycosyltransferase \\
\hline$E A M \_2169$ & ams $C$ & 0.26 & 0.17 & 5.6 & 0.19 & Amylovoran oligosaccharide repeat unit polymerase \\
\hline$E A M \_2168$ & $a m s D$ & 0.27 & 0.14 & $2.5^{\mathrm{b}}$ & 0.11 & Amylovoran biosynthesis glycosyltransferase \\
\hline$E A M \_2167$ & amsE & 0.32 & 0.23 & 3.9 & 0.17 & Amylovoran biosynthesis glycosyltransferase \\
\hline$E A M \_2166$ & $a m s F$ & 0.25 & 0.17 & 2.8 & 0.14 & Amylovoran biosynthesis protein \\
\hline EAM_2174 & $a m s G$ & 0.29 & 0.14 & 3.0 & 0.11 & UDP-galactose-lipid carrier transferase \\
\hline EAM_2173 & $a m s H$ & 0.28 & 0.27 & 4.5 & 0.43 & Amylovoran export protein \\
\hline EAM_2172 & amsI & 0.36 & 0.29 & 2.7 & 0.28 & Amylovoran biosynthesis protein-tyrosine-phosphatase \\
\hline$E A M \_2165$ & ams $J$ & 0.27 & 0.30 & 2.1 & $0.53^{\mathrm{c}}$ & Amylovoran biosynthesis protein \\
\hline$E A M \_2164$ & amsK & 0.76 & $1.25^{\mathrm{c}}$ & 2.3 & 0.49 & Amylovoran biosynthesis glycosyltransferase \\
\hline$E A M \_2163$ & $a m s L$ & 0.52 & $0.49^{c}$ & 2.5 & $0.63^{\mathrm{c}}$ & Amylovoran biosynthesis protein \\
\hline$E A M \_2161$ & galE & 0.44 & 0.42 & $1.39^{\mathrm{c}}$ & $0.53^{\mathrm{c}}$ & UDP-glucose 4-epimerase \\
\hline$E A M \_2162$ & galF & 0.29 & 0.32 & 1.85 & 0.57 & UTP-glucose-1-phosphate uridylyltransferase \\
\hline EAM_0255 & & 0.15 & 0.2 & 2.56 & 0.16 & Membrane protein \\
\hline EAM_0256 & & 0.41 & 0.40 & $1.0^{\mathrm{c}}$ & 0.36 & Lipoprotein \\
\hline EAM_1941 & $w b a P$ & 0.18 & 0.08 & 13.1 & 0.17 & UDP-Gal::undecaprenolphosphate Gal-1-P transferase \\
\hline$E A M \_1733$ & $o s m B$ & 0.25 & 0.21 & 2.72 & 0.40 & Osmotically-inducible lipoprotein B \\
\hline EAM_2938 & & 0.29 & 0.20 & $0.61^{\mathrm{c}}$ & 0.17 & Membrane protein \\
\hline EAM_2937 & & 0.30 & 0.20 & 0.47 & 0.15 & Disulfide bond formation membrane protein \\
\hline EAM_0142 & oxyR & 0.32 & 0.22 & 0.23 & 0.19 & Hydrogen peroxide-inducible genes activator \\
\hline
\end{tabular}

${ }^{a}$ Expression ratio $\geq 2.0$ indicates genes are up-regulated in mutants and $\leq 0.5$ indicates genes are down-regulated in mutants.

b MBMA medium as defined by Wang and associates (2009).

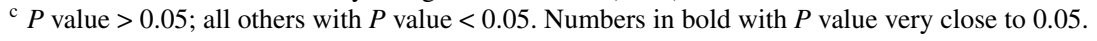


and in MBMA medium (Wang et al. 2009). Under both treatment conditions, there was no detected expression of either $r c s B$ or $\operatorname{rcs} C$ genes in their respective mutants (Table 1). Microarray data analyses revealed that for the $\operatorname{rcs} B$ mutant, 101 and 71 genes were significantly differentially expressed on pear fruits and in MBMA minimal medium, respectively (Fig. 1; Supplementary Table S1); whereas for the $\operatorname{rcs} C$ mutant, 64 and 551 genes showed significant changes on pear fruits and in MBMA medium, respectively (Fig. 1). Further analyses of all comparisons revealed that at least 12 genes were commonly differentially expressed, including nine amylovoran biosynthetic and regulatory genes ( $a m s A, a m s B, a m s C, a m s E, a m s F$, $a m s G, a m s H$, amsI, and $r c s A$ ), a polysaccharide biosynthetic gene wbaP (EAM_1941), and two genes (EAM_0255 and $\left.E A M \_2937\right)$ annotated as encoding membrane proteins (Tables 1,2 , and 3). In total, 648 genes were identified in all four comparisons.

\section{Common genes differentially expressed in the $\operatorname{rcs} B$ and $r \operatorname{rs} C$ mutants.}

To gain more insight into the regulatory mechanisms of $\mathrm{RcsB}$ and RcsC, we compared differentially expressed genes between the $r \operatorname{cs} C$ and $r \operatorname{cs} B$ mutants under in vivo or in vitro conditions. A total of 120 genes were significantly differentially expressed in the $r \operatorname{cs} B$ and $r c s C$ mutants during early pear fruit colonization (Fig. 2A). Among them, 45 genes (37.5\%) were commonly identified as being differentially expressed in both the $\operatorname{rcs} C$ and $r \operatorname{cs} B$ mutants, and of these, 26 showed lower levels of expression in the $\operatorname{rcs} B$ and $r \operatorname{cs} C$ mutants compared with the WT strain. These included 11 polysaccharide biosynthetic and regulatory genes (amsA, amsB, ams $C$, amsE, amsF, ams $G$, ams H, amsI, amsJ, glaE, galF, and $r c s A$ ), two cell-wall biosynthetic genes ( $w b a P$ and $m l t E$ ), and 10 genes annotated as genes encoding membrane proteins and lipoproteins (Tables 1 and 2). The remaining 19 genes were expressed at higher levels in the $r \operatorname{cs} B$ and $r \operatorname{cs} C$ mutants compared with the WT and included eight phosphate-related ABC transporter genes (proV, proX, pst $C$, pst $S, u g p B$, and $u g p C)$ and regulatory genes $(g \ln K$ and $p h o B)$, and a single phosphatase gene ( $p h o A)$ (Table 2). These results support our previous findings that $r \operatorname{cs} B$ and $r c s C$ mutants are nonpathogenic on immature pear due to a lack of amylovoran biosynthesis and, further, suggest that the Rcs system may control cell-envelope or membrane integrity. Due to a lack of amylovoran, mutant cells may be protected from phosphate homeostasis by increasing $\mathrm{ABC}$ transporter gene expression.

In contrast, a total of 572 genes were significantly differentially expressed in the $\operatorname{rcs} B$ and $\operatorname{rcs} C$ mutants in MBMA medium. Among them, 50 genes were found to be regulated in both the $r c s C$ and $r c s B$ mutants (Fig. 2B). Of these 50 genes, 35 were expressed at either lower or higher levels in both $r c s B$ and $r c s C$ mutants. These included $h r p$-type III secretion (T3SS) and regulatory genes ( $h r p A, h r p B, h r p F$, $h r p G$, and $h r p L$ ) (Table 3). A total of 15 genes were up-regulated in the $\operatorname{rcs} C$ mutant but were down-regulated in the $\operatorname{rcs} B$ mutant, as compared with the WT strain (Table 3 ). This group of genes contained nine amylovoran biosynthetic and regulatory genes $(r c s A$ and $a m s A, a m s B, a m s C$, ams $E, a m s F$,

Table 2. Differentially expressed common genes on immature pear fruits ${ }^{\mathrm{a}}$

\begin{tabular}{|c|c|c|c|c|}
\hline Gene ID & Gene & $\Delta r c s C / \mathbf{W T}^{\mathrm{b}}$ & $\Delta r c s B / W^{b}{ }^{b}$ & Protein description \\
\hline \multicolumn{5}{|l|}{ Group I } \\
\hline EAM_0255 & & 0.15 & 0.20 & Membrane protein \\
\hline EAM_O256 & & 0.41 & 0.40 & Lipoprotein \\
\hline$E A M \_1483$ & & 0.14 & 0.04 & Membrane protein \\
\hline$E A M_{-} 1530$ & $m l t E$ & 0.21 & 0.15 & Membrane-bound lytic murein transglycosylase E \\
\hline$E A M \_1646$ & ppsA & 0.30 & 0.26 & Phosphoenolpyruvate synthase \\
\hline$E A M \_1733$ & osmB & 0.25 & 0.21 & Osmotically-inducible lipoprotein B \\
\hline EAM_1941 & $w b a P$ & 0.18 & 0.08 & UDP-Gal::undecaprenolphosphate Gal-1-P transferase \\
\hline$E A M \_1971$ & & 0.38 & 0.46 & Exported protein \\
\hline$E A M \_2368$ & & 0.44 & 0.40 & Lipoprotein \\
\hline$E A M \_2592$ & & 0.36 & 0.41 & Hypothetical protein \\
\hline$E A M \_2720$ & & 0.49 & 0.45 & Possible lipoprotein \\
\hline$E A M \_2912$ & & 0.46 & 0.43 & Hypothetical protein \\
\hline$E A M \_2937$ & & 0.31 & 0.20 & Disulfide bond formation membrane protein \\
\hline$E A M \_2938$ & & 0.29 & 0.20 & Membrane protein \\
\hline$E A M \_3434$ & & 0.25 & 0.18 & Outer membrane protein \\
\hline \multicolumn{5}{|l|}{ Group II } \\
\hline EAM_0441 & purA & 2.03 & 2.51 & Adenylosuccinate synthetase \\
\hline EAM_0949 & phoB & 3.54 & 3.55 & Phosphate regulon response regulator \\
\hline EAM_1004 & $g \ln K$ & 2.48 & 6.67 & Nitrogen regulatory protein P-II \\
\hline$E A M \_1612$ & spy & 3.97 & 4.01 & Exported protein \\
\hline$E A M 1877$ & $\operatorname{trpE}$ & 2.34 & 3.66 & Anthranilate synthase component I \\
\hline$E A M \_1879$ & $\operatorname{trpD}$ & 3.31 & 6.11 & Anthranilate phosphoribosyltransferase \\
\hline$E A M \_1880$ & $\operatorname{trpC}$ & 2.01 & 2.76 & Anthranilate isomerase \\
\hline$E A M \_2052$ & phoA & 6.30 & 7.35 & Alkaline phosphatase \\
\hline$E A M \_2156$ & $r f b B$ & 2.02 & 2.01 & O-antigen export system ATP-binding protein \\
\hline$E A M \_2598$ & proV & 4.20 & 2.88 & Glycine betaine/l-proline $\mathrm{ABC}$ transporter \\
\hline$E A M \_2600$ & proX & 3.48 & 2.58 & Glycine betaine/L-proline $\mathrm{ABC}$ transporter \\
\hline$E A M+2619$ & & 3.97 & 4.33 & Hypothetical protein \\
\hline$E A M \_2620$ & tyrA & 5.49 & 5.80 & T-protein \\
\hline$E A M \_2621$ & aroF & 4.16 & 7.40 & Deoxyheptonate aldolase, Tyr-sensitive \\
\hline$E A M \_3065$ & $\operatorname{deaD}$ & 2.32 & 2.35 & ATP-dependent RNA helicase \\
\hline$E A M \_3282$ & ugpC & 2.92 & 2.49 & Glycerol-3-phosphate $\mathrm{ABC}$ transporter \\
\hline$E A M+3285$ & ugpB & 5.12 & 5.75 & Glycerol-3-phosphate $\mathrm{ABC}$ transporter \\
\hline$E A M \_3466$ & pstC & 2.21 & 2.36 & Phosphate $\mathrm{ABC}$ transporter \\
\hline$E A M \_3467$ & pst $S$ & 3.56 & 5.16 & Phosphate $\mathrm{ABC}$ transporter \\
\hline
\end{tabular}

\footnotetext{
${ }^{\text {a } P \text { value }<0.05}$
}

${ }^{\mathrm{b}}$ Expression ratio $\geq 2.0$ indicates genes are up-regulated in mutants and $\leq 0.5$ indicates genes are down-regulated in mutants. WT $=$ wild type. 
ams $G$, ams $H$, and amsI), one cell-wall biosynthetic gene $(w b a P)$, and one gene (EAM_0255) annotated as encoding a membrane protein. These results were consistent with our previous findings that showed increased amylovoran production in the $\operatorname{rcs} C$ mutant but no detectable amylovoran in the $r c s B$ mutant (Wang et al. 2009). Our results also indicate a potential cross-talk between the Rcs phosphorelay system and the T3SS system in vitro.

\section{Common genes differentially expressed both in vitro and in vivo in either $\operatorname{rcs} B$ or $\operatorname{rcs} C$ mutants.}

A total of 155 genes belonging to the RcsB regulon were identified under in vitro and in vivo conditions (Fig. 2C). Among them, 17 genes were commonly regulated in both conditions, and all were expressed at a lower level in the $\operatorname{rcs} B$ mutant when compared with the WT strain. These genes included nine polysaccharide-related genes (seven ams operon genes, $r c s A$, and $w b a P$ ), five membrane-encoding protein genes (EAM_0255, EAM_1483,EAM_2937, EAM_2938, and $\left.E A M \_3434\right)$, a regulatory gene $0 x y R$ (EAM_0142), EAM_0510, and EAM_0511 (sulfate transporter) (Table 2), indicating that these genes were under positive control of RcsB. Interestingly, cell-envelope stress-responsive regulator genes cpxRl (EAM $0100)$ and $c p x R 2$ (EAM_2395) and a putative responsive regulator gene (EAM_2359) were up-regulated in the $r \operatorname{cs} B$ mutant in vivo but not in vitro.

In contrary, a total of 593 genes belonging to the $\mathrm{RcsC}$ regulon were identified under both in vitro and in vivo conditions (Fig. 2D). Among them, 22 genes were regulated in both conditions. However, these genes exhibited inverse expression patterns in vitro and in vivo. Of these, 15 genes exhibited higher levels of expression in vitro but lower levels of expression in vivo, including eight ams biosynthetic genes (amsA, ams B, ams C, amsE, ams F, ams G, amsH, and amsI), rcsA (Table 1), wbaP (EAM_1941), osmB (EAM_1733, an osmotically inducible lipoprotein B), and EAM_0255. The other six genes, all involved in amino-acid biosynthesis and including hisD (EAM_2142), trpCDE (EAM_1877-1880), and leuAB (EAM_0682-0683), were significantly up-regulated in the $\operatorname{rcs} C$ mutant on pear fruits but down-regulated in the $\operatorname{rcs} C$ mutant in MBMA medium. The remaining gene EAM_2937 (and $E A M \_2938$ ), encoding a disulfide bond formation membrane protein, exhibited lower levels of expression in the $\operatorname{rcs} C$ mutant under both conditions. These results indicated that $\mathrm{RcsC}$

Table 3. Differentially expressed common genes in MBMA medium

\begin{tabular}{|c|c|c|c|c|}
\hline Gene ID & Gene & $\Delta r c s C / \mathrm{WT}^{\mathrm{b}}$ & $\Delta r c s B / W^{b}{ }^{b}$ & Protein description \\
\hline \multicolumn{5}{|l|}{ Group I } \\
\hline EAM_0255 & & 2.56 & 0.16 & Membrane protein \\
\hline EAM_0648 & & 2.20 & 0.19 & Acyltransferase \\
\hline$E A M \_1474$ & & 2.79 & 0.34 & Exported protein \\
\hline$E A M \_1941$ & wbaP & 13.14 & 0.17 & UDP-Gal::undecaprenolphosphate Gal-1-P transferase \\
\hline$E A M \_2036$ & ots $B$ & 2.19 & 0.36 & Trehalose phosphatase \\
\hline EAM_2948 & & 7.41 & 0.21 & Fimbrial protein \\
\hline \multicolumn{5}{|l|}{ Group II } \\
\hline EAM_0060 & & 0.17 & 0.44 & Cytosine-specific DNA methylase \\
\hline$E A M \_0061$ & & 0.09 & 0.38 & Restriction enzyme \\
\hline EAM_0110 & & 0.09 & 0.33 & Hypothetical protein \\
\hline EAM_O142 & $\operatorname{oxy} R$ & 0.23 & 0.19 & Hydrogen peroxide-inducible genes activator \\
\hline EAM_0288 & & 0.34 & 0.42 & Bactoprenol-linked glucose transferase \\
\hline EAM_0931 & & 0.37 & 0.35 & Hypothetical protein \\
\hline$E A M \_1208$ & & 0.33 & 0.42 & Zinc-binding dehydrogenase \\
\hline EAM_1378 & sulA & 0.12 & 0.37 & Cell division inhibitor \\
\hline$E A M \_1393$ & & 0.48 & 0.44 & Hypothetical protein \\
\hline$E A M \_1413$ & & 0.30 & 0.24 & Hypothetical protein \\
\hline EAM_1414 & & 0.31 & 0.26 & Hypothetical protein \\
\hline$E A M_{-} 1527$ & & 0.28 & 0.40 & Phage protein \\
\hline$E A M \_1876$ & $\operatorname{trpH}$ & 0.45 & 0.44 & Phosphoesterase \\
\hline$E A M \_2146$ & hisA & 0.28 & 0.38 & $\begin{array}{l}\text { 1-(5-phosphoribosyl)-5-[(5-phosphoribosylamino) } \\
\text { methylideneamino imidazole-4-carboxamide isomerase }\end{array}$ \\
\hline$E A M \_2404$ & amiA & 0.36 & 0.32 & $\mathrm{~N}$-acetylmuramoyl-L-alanine amidase \\
\hline$E A M \_2493$ & & 0.29 & 0.37 & Transcriptional regulator \\
\hline EAM_2529 & $\operatorname{recN}$ & 0.11 & 0.31 & DNA repair protein \\
\hline$E A M \_2647$ & & 0.19 & 0.36 & Transcriptional regulator \\
\hline$E A M \_2874$ & & 0.21 & 0.31 & Type III secretion system protein \\
\hline$E A M \_2876$ & & 0.21 & 0.26 & OrfB-specific chaperone \\
\hline$E A M \_2881$ & hrpG & 0.21 & 0.25 & Type III secretion system protein \\
\hline$E A M+2882$ & hrpF & 0.19 & 0.20 & Type III secretion system protein \\
\hline$E A M \_2886$ & hrpB & 0.08 & 0.24 & Type III secretion system protein \\
\hline$E A M \quad 2887$ & hrpA & 0.14 & 0.28 & Type III secretion system protein \\
\hline$E A M \_2894$ & hrpL & 0.12 & 0.23 & Sigma factor HrpL \\
\hline$E A M \_2900$ & hrpP & 0.19 & 0.27 & Type III secretion system protein \\
\hline$E A M \_2937$ & & 0.47 & 0.15 & Disulfide bond formation membrane protein \\
\hline$E A M \_3259$ & gnt $Y$ & 0.40 & 0.28 & $\mathrm{Fe}-\mathrm{S}$ protein \\
\hline$E A M+3438$ & & 0.20 & 0.16 & Sugar isomerase \\
\hline$E A M \_3439$ & & 0.48 & 0.27 & Carbohydrate kinase \\
\hline \multicolumn{5}{|l|}{ Group III } \\
\hline EAM_0488 & & 4.28 & 3.12 & Hypothetical protein \\
\hline$E A M \_1683$ & gst & 8.08 & 2.56 & Glutathione S-transferase \\
\hline$E A M-1711$ & & 11.94 & 2.96 & Dethiobiotin synthetase \\
\hline$E A M \_1884$ & отр $W$ & 5.26 & 2.97 & Outer membrane protein $\mathrm{W}$ \\
\hline$E A M \_2194$ & & 2.26 & 3.32 & Hypothetical protein \\
\hline
\end{tabular}

\footnotetext{
${ }^{\text {a }}$ MBMA medium as defined by Wang and associates (2009). The $P$ value $<0.05$; genes shown in bold indicate RcsAB box in their promoters.
}

${ }^{\mathrm{b}}$ Expression ratio $\geq 2.0$ indicates genes are up-regulated in mutants and $\leq 0.5$ indicates genes are down-regulated in mutants. WT $=$ wild type. 
appeared to have a different regulatory mechanism under in vitro and in vivo conditions.

\section{Other important genes regulated}

by $\mathrm{RcsC}$ in vitro but not in vivo.

With large numbers of genes identified in the $r \operatorname{cs} C$ mutant in vitro, other major groups of genes regulated by $\mathrm{RcsC}$ were further analyzed, and these include the following categories. i) Cell envelope (membrane protein-encoding genes). A total of 34 genes similar to those encoding membrane proteins were differentially expressed in the $r \operatorname{cs} C$ mutant in vitro. Two membrane protein-encoding genes, EAM_0322 and EAM_0323, expressed at levels 41- and 25-fold higher, respectively, in the $r c s C$ mutant than in WT grown in MBMA medium, further suggesting a role for $\mathrm{RcsC}$ in alterations to the bacterial cell surface. ii) Glycogen biosynthesis. Genes similar to glycogen synthesis and debranching ( $\lg \lg A B C P X$ (EAM_3268-3272) were up-regulated in the $\operatorname{rcs} C$ mutant in vitro (Fig. 3A). iii) Signal transduction and regulation. Both OmpR and HrpS are negative regulators of amylovoran production (Zhao et al. 2009a and b). Transcripts of ompR and $h r p S$ genes exhibited two- to threefold lower levels of expression in the $\operatorname{rcs} C$ mutant in MBMA medium compared with the WT strain, partially explaining the excessive amylovoran production phenotype in vitro. iv) T3SS and flagellar genes. Interestingly, $h r p$-T3SS genes appeared to be influenced by the $\operatorname{rcs} C$ gene in vitro. A total of $18 \mathrm{hrp}$-related genes exhibited lower levels of expression in the $\operatorname{rcs} C$ mutant in vitro, including the master regulator $h r p L$ as well as structural, effector, and helper genes $h r p A$, $h r p N$, avrRpt2, dspE, and hrpW (Table 3; Fig. 3A). Downregulation of hrpS transcripts might result in lower levels of expression of $h r p L$ and other T3SS genes in MBMA medium, further suggesting the possible cross-talk between T3SS and amylovoran biosynthesis. In addition, the $f l h D$ and $f l h C$ genes, encoding the master regulator of flagella, and many other flagellar genes were also expressed at levels at least twofold lower in the $r c s C$ mutant in MBMA medium.

In contrary, eight hrp genes but not $f l h D$ and $f l h C$, which were not significantly changed, exhibited lower expression in the $\operatorname{rcs} B$ mutant in vitro (Table 3 ). It has been reported that RcsB negatively regulates the expression of $f l h D$ and $f l h C$ genes by binding to the promoter of the $f \operatorname{lh} D C$ operon as a suppressor in Escherichia coli (Majdalani and Gottesman 2005). Interestingly, the expression of $f l h D$ and $f l h C$ was three to fourfold higher in the $\operatorname{rcs} B$ mutant in vivo as compared with the WT strain (Table 4), suggesting RcsB is also a suppressor of $f l h D$ and flhC expression in E. amylovora.
Validation of microarray data by quantitative real-time PCR (qRT-PCR).

To validate microarray data, a two-step qRT-PCR was performed for eight genes, including $r c s A$, ams $G$, ams $C$, $a m s D$, $g \lg B, g \lg C, d s p E$, and $h r p N$. The resulting transcriptional fold changes from qRT-PCR analyses for all selected genes were comparable to those obtained by microarray analyses (Fig. 3), validating the microarray data.

\section{Differential expression of $r c s$ genes}

in Luria Bertani (LB) medium, MBMA, and pear fruits.

RcsA is a rate-limiting regulator of amylovoran biosynthesis in E. amylovora (Bernhard et al. 1990). Our microarray analyses have revealed that the expression level of $\operatorname{rcs} A$ in MBMA medium was twofold higher in the $\operatorname{rcs} C$ mutant but was significantly lower (50-fold) in the $\operatorname{rcs} B$ mutant, when compared with those of the WT strain (Table 1). In addition, the expression level of the $\operatorname{rcs} A$ gene was four- and 20-fold lower in the $r \operatorname{cs} C$ and $r c s B$ mutants in vivo, respectively (Table 1 ). These results suggest that the impact of RcsB and RcsC on amylovoran production in vitro may be mediated by regulating $r \operatorname{cs} A$ expression. As expression profiles for the ams genes are highly similar to those of $r \operatorname{cs} A$, indicating that $\mathrm{RcsB}$ directly regulates RcsA expression by binding to the promoter of $r c s A$, as reported previously (Bernhard et al. 1990), and suggesting that both RcsC and RcsB act as positive regulators to promote ams gene expression during infection of immature pear fruits.

qRT-PCR experiments were also carried out to determine the relative transcript abundance of $r \operatorname{cs} A, r \operatorname{cs} B, r c s C$, and $r c s D$ genes in the WT strain under different growth conditions. Expression of $r c s A, r c s C$, and $r c s D$ was significantly up-regulated in MBMA medium and on pear fruits compared with those of the LB medium (Fig. 4). Interestingly, expression of $r c s B$ was not significantly altered under all three conditions, suggesting $\operatorname{rcs} B$ is not regulated at the transcriptional level during E. amylovora infection.

\section{Identification of $R \operatorname{csB}$ promoters}

in E. amylovora, using hidden Markov modeling.

It has been demonstrated that phosphorylated RcsB in $E$. amylovora binds to an RcsAB box (TaAGaatatTCctA) to regulate gene expression as RcsB-RcsB homodimers or RcsAB heterodimers (Wehland et al. 1999; Wehland and Berngard 2000). To complement microarray data, the presence and distribution of the $r \operatorname{cs} B$ box consensus sequence within the genome of ATCC 49946 were investigated. A hidden Markov model (HMM) was created from multiple sequence alignments
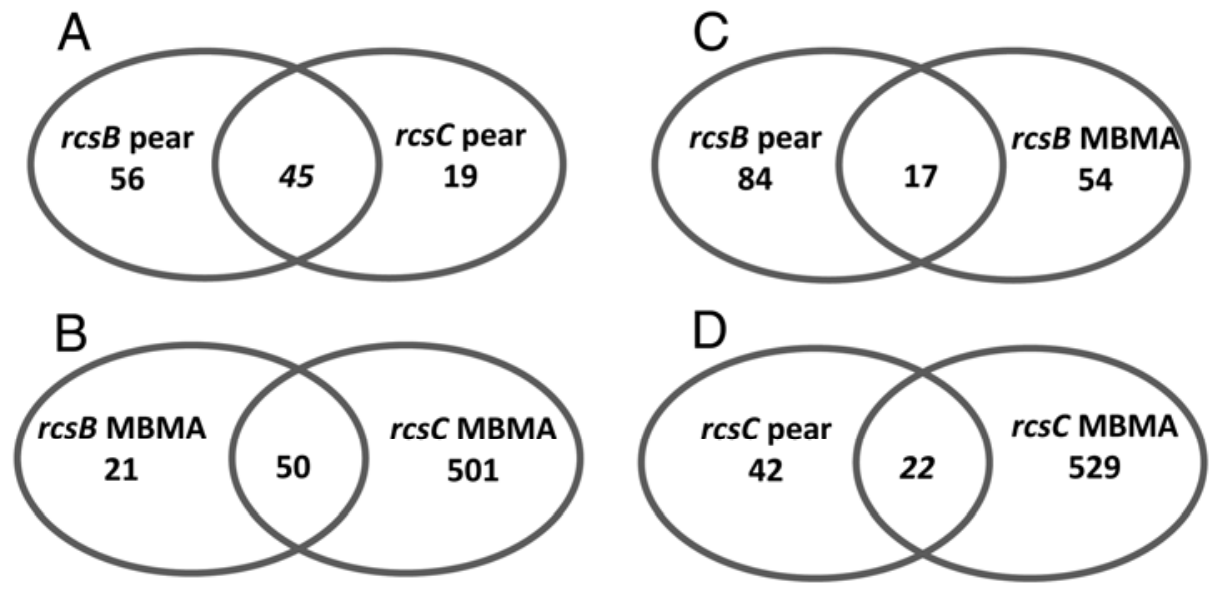

Fig. 2. Generalized Venn diagram showing the number of genes regulated by RcsB and RcsC. A, and $\mathbf{B}, \Delta r c s B / W T$ and $\Delta r c s C / W T$ in vivo and in vitro, respectively, $\mathbf{C}, \triangle r c s B / \mathrm{WT}$ in vivo and in vitro, and $\mathbf{D}, \Delta r c s C / \mathrm{WT}$ in vivo and in vitro. 
of 17 RcsB boxes from six enterobacterial species, and 60 genes were predicted to contain a potential RcsB box with a bit-score classifier threshold $>13$ (Table 4; Supplementary Table S2). Promoters of two genes ( $r \operatorname{cs} D$ and $r c s A$ ) with predicted RcsB boxes overlap with coding sequences of upstream genes.

By comparing microarray data of RcsB regulons under both conditions, 18 genes containing RcsB boxes were either in-
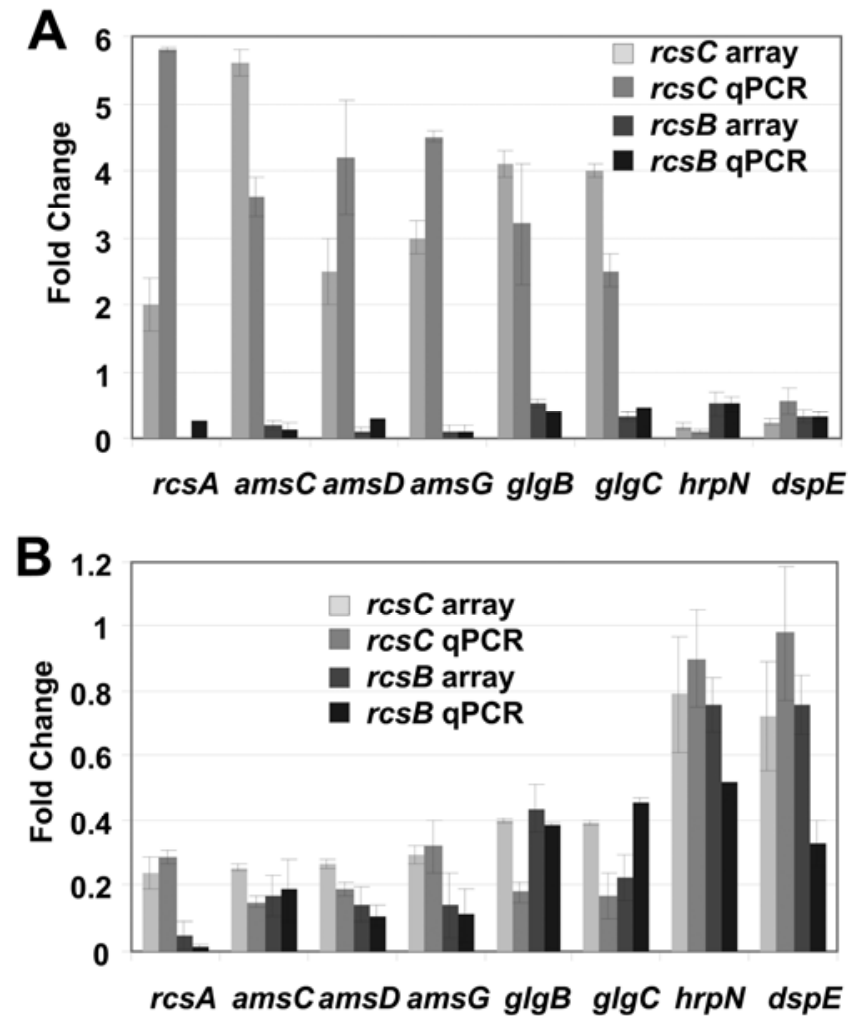

Fig. 3. Verification of microarray data by quantitative reverse transcription-polymerase chain reaction (qRT-PCR). A, The relative fold change of each gene was derived from the comparison of the $r \operatorname{cs} B$ and $r \operatorname{cs} C$ mutants versus the wild-type strain in MBMA medium (Wang et al. 2009) and B, immature pear fruits. The $16 \mathrm{~S}$ rDNA $(r r s A)$ gene was used as an endogenous control in qRT-PCR. The values of relative fold change were means of three replicates. The experiments were repeated three times with similar results. Error bars indicate standard deviation. creased or decreased in expression in the $\operatorname{rcs} B$ mutant (Table 4). Among them, 11 genes were decreased in expression in the $r c s B$ mutant in both conditions, including $a m s G, r c s A$, EAM_0255, EAM_2938,EAM_1474, and EAM_1483. Five genes were increased in expression in the $\operatorname{rcs} B$ mutant, including $f l h D$ and $l s c$ (encoding levansucrase). Another 10 genes were differentially regulated in the $r \operatorname{cs} C$ mutant in vitro.

\section{In silico comparisons}

of two operons $\left(E A M \_0255\right.$ and $\left.E A M \_2938\right)$.

Genes putatively encoding membrane proteins are major components of the RcsBC regulon, suggesting their importance in signal transduction and biology of E. amylovora. Initial BLAST searches have revealed that several membrane proteins we identified in this study are only found in $E$. amylovora and the related pear pathogen E. pyrifoliae, including EAM_0255 and EAM_2938. The latter has recently been identified as one of the HrpL-regulated genes and contributes to virulence as a novel virulence factor (McNally et al. 2011). Bioinformatic analyses have predicted that EAM_2938, along

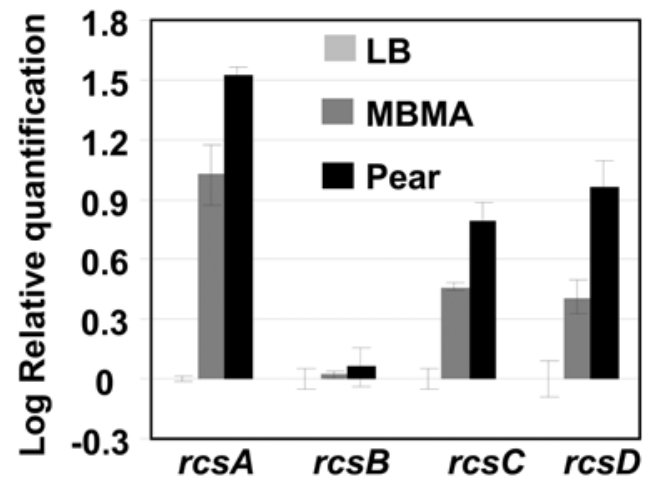

Fig. 4. The relative abundance of $r c s A, r c s B, r c s C$, and $r c s D$ mRNA under different growth conditions. The relative fold change of each gene was derived from the comparison of wild-type strain grown in MBMA medium (Wang et al. 2009) or immature pear fruits compared with that in Luria Bertani medium. The $16 \mathrm{~S}$ rDNA ( $r r s$ ) gene was used as an endogenous control in quantitative reverse transcription-polymerase chain reaction. The relative fold change values were means of three replicates. The experiments were repeated three times with similar results and only one result was presented. Error bars indicate standard deviation.

Table 4. Hidden Markov model-predicted genes with RcsAB box and microarray results ${ }^{\mathrm{a}}$

\begin{tabular}{|c|c|c|c|c|c|c|c|}
\hline Gene ID & Gene & Score $(>13)$ & $r c s B / W T$ in vivo & $P$ value & $r c s B / W T$ in vitro & $P$ value & Protein description \\
\hline EAM_0255 & $\ldots$ & 13.13 & 0.2 & 0 & 0.16 & 0.02 & Membrane protein \\
\hline EAM_0510 & $\ldots$ & 16.93 & 0.29 & 0.01 & 0.16 & 0.04 & Carbonic anhydrase \\
\hline$E A M \_0648$ & $\ldots$ & 14.11 & 0.16 & 0.12 & 0.19 & 0.02 & Acyltransferase \\
\hline EAM_0910 & $\ldots$ & 16.16 & 0.25 & 0.03 & 0.53 & 0.09 & Methyltransferase \\
\hline$E A M \_1474$ & $\ldots$ & 13.42 & 0.15 & 0.08 & 0.34 & 0.03 & Exported protein \\
\hline$E A M_{-} 1482$ & $\operatorname{rcs} A^{\mathrm{b}}$ & 17.39 & 0.05 & 0 & 0.02 & 0 & $\begin{array}{l}\text { Colanic acid capsular biosynthesis } \\
\text { activation protein } \mathrm{A}\end{array}$ \\
\hline$E A M \_1483$ & $\ldots$ & 15.35 & 0.04 & 0 & 0.02 & 0.01 & Membrane protein \\
\hline$E A M \_1499$ & $\ldots$ & 13.21 & 2.34 & 0.03 & 1.19 & 0.68 & Hypothetical protein \\
\hline$E A M \_1646$ & ppsA & 15.04 & 0.26 & 0.03 & 0.32 & 0.0 & Phosphoenolpyruvate synthase \\
\hline$E A M \_1744$ & mqo & 17.12 & 2.15 & 0.03 & 0.50 & 0.14 & Malate:quinone oxidoreductase \\
\hline$E A M_{-} 1868$ & $\ldots$ & 16.33 & 1.32 & 0.27 & 0.2 & 0.02 & Hypothetical protein \\
\hline$E A M \_2034$ & $f l h D$ & 15.22 & 4.32 & 0.03 & 0.9 & 0.45 & Flagellar transcriptional activator \\
\hline$E A M \_2062$ & $\ldots$ & 15.74 & 0.09 & 0.09 & 0.49 & 0.06 & Acyltransferase \\
\hline$E A M \_2174$ & $a m s G$ & 16.49 & 0.14 & 0.06 & 0.11 & 0.01 & UDP-galactose-lipid carrier transferase \\
\hline$E A M \_2194$ & $\ldots$ & 17.31 & 0.95 & 0.84 & 3.32 & 0.03 & Hypothetical protein \\
\hline$E A M \_2938$ & $\ldots$ & 14.12 & 0.2 & 0.01 & 0.17 & 0.03 & Membrane protein \\
\hline$E A M \_2948$ & $\ldots$ & 13.24 & 0.2 & 0.06 & 0.21 & 0.03 & Fimbrial protein \\
\hline$E A M \_3468$ & $l s c$ & 13.36 & 2.49 & 0.02 & 1.78 & 0.06 & Levansucrase \\
\hline
\end{tabular}

\footnotetext{
${ }^{\text {a }}$ Expression ratio $\geq 2.0$ indicates genes are up-regulated in mutants and $\leq 0.5$ indicates genes are down-regulated in mutants.
}

$\mathrm{b}$ The promoter sequence is overlapped with the coding sequence of upstream gene. 
with $E A M \_2937$ and $E A M \_2936$, forms an operon (McNally et al. 2011). Similar to the EAM_2938 operon, EAM_0255 is also predicted as the first open-reading frame in an operon (Supplementary Fig. S1). The EAM_O255 operon contains EAM_0256 and EAM_0257 but not EAM_0258, which is highly similar to that of EAM_2935 (McNally et al. 2011). In addition, EAM_0322 along with EAM_0323 and EAM_0324 has highly similar gene organization to EAM_0255 and EAM_2938 operons, but they do not form an operon.

The average GC content for the EAM_2938 operon (42 to $49 \%$ ) is lower than that for the genome of E. amylovora (53.6\%) (McNally et al. 2011), indicating it may have been recently acquired by the E. amylovora genome. However, the GC content of the EAM_0255 operon as well as the EAM_0322 locus is similar to the overall Erwinia genome. With the exception of EAM_0255 and EAM_2938, homologs of all other genes exist widely in other enterobacteria. In addition, all genes in the EAM_0255 operon contain a signal peptide and $E A M \_0255$ encodes for a membrane protein with two transmembrane helices, whereas EAM_0256 and EAM_0258 encode lipoproteins, and each contains a lipoprotein lipid attachment site. The closest homologs to the genes within the EAM_0255 operon in Escherichia coli are operons yjbEFGH and $y m c A B C D$, which function in CPS (lipopolysaccharide) assembly and export (Cuthbertson et al. 2009; Peleg et al. 2005). EAM_0322 and EAM_0323 encode murein hydrolase- like proteins $\operatorname{LrgA}$ and $\operatorname{LrgB}$, respectively. Interestingly, it seems that EAM_2936,EAM_0257, and EAM_0324 all contain a signal peptide, indicating that they all encode a putative exported protein.

\section{DISCUSSION}

The Rcs phosphorelay system is a complex and widely studied signal transduction pathway found in members of family Enterobacteriaceae (Clarke 2010). In E. amylovora, the Rcs system is an essential regulatory system for pathogenicity and gene expression of virulence factors, especially of amylovoran (Wang et al. 2009, 2011; Zhao and Qi 2011). Transcriptomic studies coupled with bioinformatic analyses in Escherichia coli, Salmonella enterica, and Yersinia pseudotuberculosis have facilitated the identification of the Rcs regulon. Moreover, this has led to the major conclusion that remodeling the bacterial cell surface may be the result of this phosphorelay in response to environmental stimuli (Erickson and Detweiler 2006; Ferrières and Clarke 2003; Hinchliffe et al. 2008). So far, most studies have been conducted under in vitro growth conditions or by overactivating the Rcs system, but there are no genome-wide gene expression studies under in vivo conditions. In this study, core RcsBC regulons in $E$. amylovora have been determined in both liquid medium and on pear fruits.
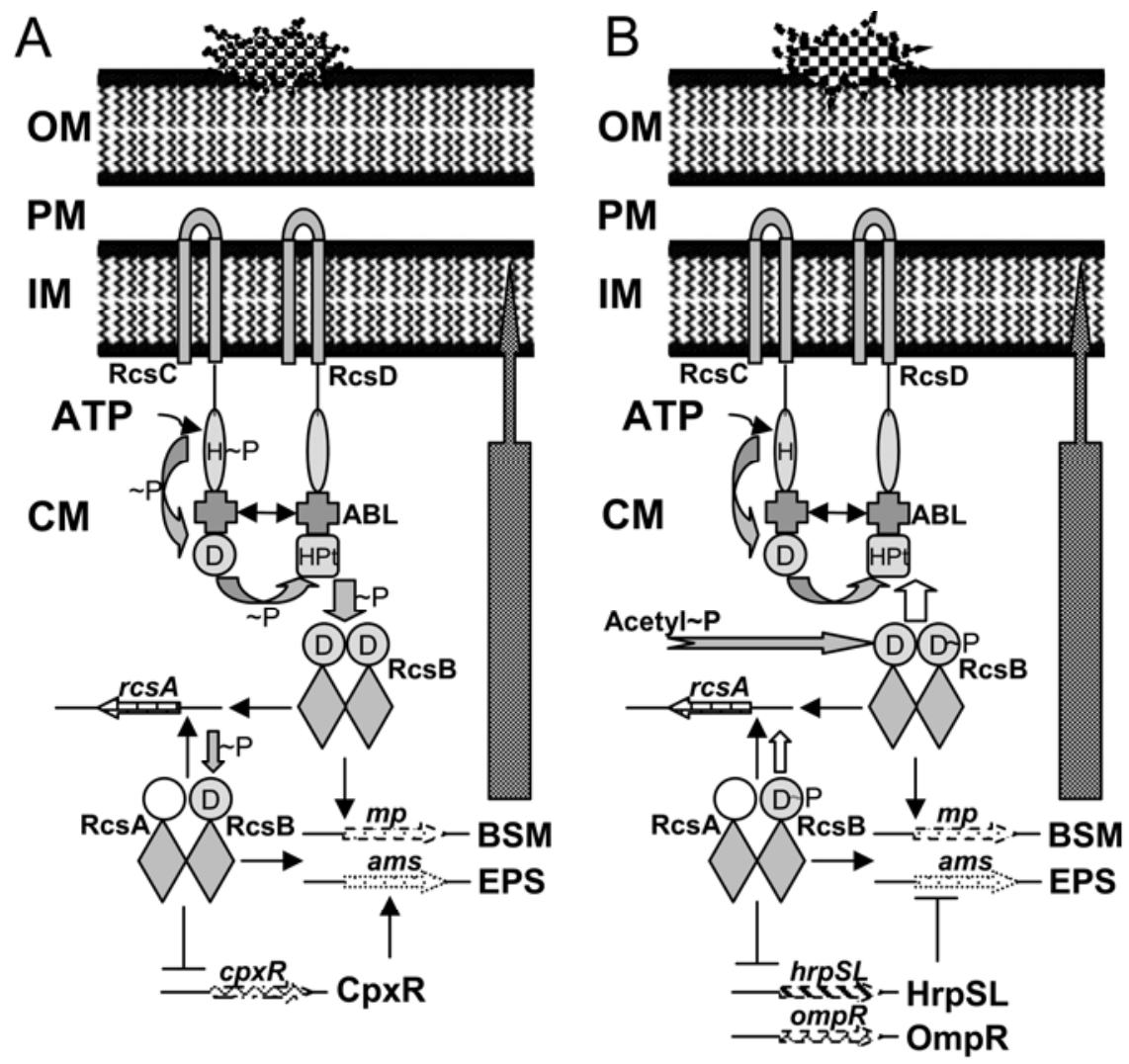

Fig. 5. A model for the Rcs phosphorelay system in Erwinia amylovora. A, During plant infection, plant signals, presumably reactive oxygen species, and host contact are perceived directly or indirectly by RcsC sensor kinase, which then phosphorylates RcsB, leading to amylovoran production, remodeling the cell surface, and disease. After activation, other regulatory systems such as the envelope stress two-component system CpxAR, which is a positive regulator of amylovoran production, may also be involved. Without RcsC, the signals cannot be sensed and other phosphor-donors are sparse, resulting in no activation of the Rcs system and disease. B, In medium, no such host-related signals exist; RcsC may act as phosphatase and dephosphorylates RcsB, but RcsB can be phosphorylated by other phospho-donors such as acetyl-P, which remains high when grown in medium. The net flow of phosphoryl group results in reduced phospho-RcsB and, thus, less amylovoran production. Without RcsC, net phospho-RcsB or the ratio of phosphor-RcsB versus nonphosphorylated RcsB increases, resulting in overactivation of the Rcs system and, thus, more amylovoran production. Overactivation of the Rcs system may suppress other regulators, such as OmpR and HrpSL; both are suppressors of amylovoran production. $\mathrm{OM}=$ outer membrane, $\mathrm{IM}=$ inner membrane, $\mathrm{PM}=$ periplasm, $\mathrm{CM}=$ cytoplasm, $\mathrm{H}=$ histidine kinase domain, $\mathrm{D}=$ receiver domain, Hpt: histidine phosphotransfer domain, $\mathrm{ABL}=\alpha-\beta$-loop domain, $\mathrm{mp}=$ genes encoding for membrane proteins or lipoproteins, EPS = exopolysaccharide amylovoran, and BSM = bacterial surface remodeling. 
A total of 648 genes differentially regulated by the RcsCB system have been identified in vitro and in vivo. Consistent with our previous findings, RcsB acts as a positive regulator of amylovoran biosynthesis under both conditions. While the RcsC controls amylovoran biosynthetic gene expression positively in vivo but negatively in vitro. Other major components of the RcsB and RcsC regulons include those genes encoding cell-wall and cell-envelope (membrane) proteins as well as regulatory proteins. These results further confirm that the Rcs system plays a significant role in remodeling the bacterial cell surface and suggest that, in response to host signals, the Rcs system may undergo a similar reaction. Furthermore, perturbations in peptidoglycan and cell membranes may lead to increased activity of the Rcs system, which may result in avoiding host defense recognition and protection from oxidative stress.

The Rcs phosphorelay system was first characterized for its role in transcriptional regulation of genes for capsular polysaccharide in Escherichia coli (Clarke et al. 2002; Jayaratne et al. 1993; Takeda et al. 2001). Later studies have demonstrated that the Rcs system is involved in regulation of a wide array of phenotypes, such as swarming motility, antibiotic resistance, biofilm formation, and virulence, especially of $S$. enterica, Pantoea stewartii, and E. amylovora (Andresen et al. 2007; Bereswill and Geider 1997; Detweiler et al. 2003; FrancezCharlot et al. 2003; Laubacher et al. 2008; Wang et al. 2009). Thus, defining the Rcs regulon in enterobacteria has been a major focus in several recent studies, but none have been reported in plant-pathogenic bacteria. These studies have identified common genes, but substantial differences in the composition of the Rcs regulon are also apparent, mainly due to the growth conditions used and the diverse mutants compared, further indicating the complexity of the Rcs system (Erickson and Detweiler 2006; Ferrières and Clarke, 2003; Hinchliffe et al. 2008; Oshima et al. 2002). The importance of the Rcs system in the pathogenicity of E. amylovora, as well as its unique in vitro phenotype, led to a characterization of the Rcs regulon in this important pathogen. These phenotypes as well as the immature pear platform (Zhao et al. 2005, 2006) provide a unique opportunity to study the mechanism of the Rcs system under both in vivo and in vitro conditions.

When cells were grown at low temperature and in the presence of both glucose and a high concentration of zinc, 32 genes were identified as members of the RcsC regulon in Escherichia coli. These included 17 genes belonging to the cps operon and eight encoding membrane, periplasm, and lipoproteins (Hagiwara et al. 2003). When comparing the $r c s C$ mutant and WT strain overexpressing the DnaJ-like protein DjlA, an activator of RcsC, a microarray analysis identified 149 genes controlled by RcsC in Escherichia coli (Ferrières and Clarke 2003). Among these genes, 75 (50\%) encoded proteins that were either localized to the envelope of Escherichia coli or were involved in modifying bacterial cell surfaces and cellenvelope structures, suggesting that $\mathrm{RcsC}$ plays crucial roles in remodeling bacterial surfaces when grown on a solid surface. Furthermore, when bacteria were grown under high-osmolarity minimal medium, 71 genes were identified in the IgaA1 mutant $(\mathrm{R} 188 \mathrm{H})$, the first mutation characterized to cause overactivation of the Rcs system (Mariscotti and Portillo 2009). Among them, 33 genes were up-regulated, including 26 genes involved in the synthesis of capsule biosynthesis, while 38 genes were down-regulated, including 26 flagellar genes and osmB, encoding an osmolarity-inducible lipoprotein B. In $Y$. pseudotuberculosis, the Rcs regulon consisted of at least 136 genes when bacteria overexpressing either RcsB or DjlA were used and grown at 28 or $37^{\circ} \mathrm{C}$ (Hinchliffe et al. 2008). Over $60 \%$ of the 136 genes encode proteins related to envelope homeostasis, including lipoproteins, membrane proteins, and lipopolysaccharide or peptidioglycan synthesis and modification (Hinchliffe et al. 2008). In this study, we identified 45 and 50 genes in vivo and in vitro, respectively, serving as Rcs regulons in E. amylovora (Fig. 2A and B; Tables 1, 2, and 3). Among those 45 in vivo differentially expressed genes, 23 (>50\%) were related to cell-envelope biogenesis (Tables 1 and 2). On the other hand, 15 of those 50 common genes found under in vitro conditions exhibited inverse regulation in the $r \operatorname{cs} C$ and $r \operatorname{cs} B$ mutants (Tables 1 and 2). A total of 12 genes (80\%) were related to cell-envelope biogenesis. When considering both in vivo and in vitro conditions, 17 and 22 genes were commonly regulated by $\mathrm{RcsB}$ and $\mathrm{RcsC}$, respectively, and 12 genes of each $(70 \%$ and $55 \%)$ were related to cell-envelope biogenesis (Fig. 2C and D). When all four combinations were compared, at least 12 genes were commonly found. Interestingly, all 12 genes were related to cell-envelope biogenesis, including eight amylovoran biosynthesis genes, rcsA, wbaP, EAM_0255, and $E A M \_2937$, and these genes had similar expression patterns, except $E A M \_2937$, which was expressed at lower levels in the $\operatorname{rcs} C$ mutant in vitro (Tables, 1,2 , and 3 ). These findings further confirm previous reports on the mechanism of Rcs regulation and indicate that remodeling of the cell surface might indeed be a major part of the Rcs regulon.

Results in this study confirmed previous reports that the $\operatorname{rcs} C$ mutant produces higher levels of amylovoran than the WT strain in vitro, as demonstrated by overexpression of amylovoran biosynthesis genes and regulatory gene $\operatorname{rcs} A$ (Wang et al. 2009, 2011). Compared with three other comparisons, relatively large numbers of genes (554 genes) in E. amylovora are significantly differentially expressed in the $\operatorname{rcs} C$ mutant in vitro. This finding is comparable to previous reports wherein either RcsB is overexpressed or RcsC is suppressed (Hinchliffe et al. 2008; Wang et al. 2007). A total of 674 and 1,384 genes are regulated by RcsB in $Y$. pseudotuberculosis at 28 and $37^{\circ} \mathrm{C}$, respectively, when either RcsB or DjlA is overexpressed (Hinchliffe et al. 2008). Similarly, 20\% of the genome of $S$. enterica is controlled by RcsB when the Rcs system can not be suppressed by IgaA (Wang et al. 2007). These similar findings suggest that deletion of $r c s C$ gene may lead to overactivating the Rcs system in vitro without the in vivo signal. It has been reported that $\mathrm{RcsC}$ also exhibits phosphatase activity in enterobacteria and a large portion of the RcsB pool is phosphorylated in the $r \operatorname{cs} C$ mutant in minimal medium (Clarke et al. 2002). Thus, it is tempting to speculate that, when the $\operatorname{rcs} C$ gene is deleted, RcsB could be phosphorylated in vitro by other phosphodonors such as acetyl phosphate (Fredericks et al. 2006), thus activating the Rcs system and promoting amylovoran biosynthesis. Many genes positively controlled by phosphorylated $\mathrm{RcsB}$, such as ams and $r c s A$, are up-regulated in the $\operatorname{rcs} C \mathrm{mu}-$ tant. However, phosphorylated RcsB suppresses expression of regulatory genes such as $f l h D, o m p R$, and $h r p S$, leading to lower levels of expression of $h r p L$, T3SS, and flagellar genes. On the other hand, another 10 genes with the RcsB boxes in their promoters are differentially regulated only in the $r c s C$ mutant in vitro, thus suggesting the presence of a likely different regulatory mechanism. Therefore, it is also possible that some genes may be regulated by a nonphosphorylated RcsB in vitro (Mariscotti and Portillo 2009). Additional work is needed to confirm whether nonphosphorylated RcsB can regulate gene expression in E. amylovora and to determine the ratio of phosphorylated RcsB and nonphosphorylated RcsB in vitro.

The hidden Markov promoter modeling for in silico genomewide identification of conserved cis elements is a useful tool for identifying genes directly regulated by RcsB (Eddy 1998). In this study, promoters of about 60 genes contain RcsB box sequences. Among them, 28 genes (about 50\%) were identified by microarray as part of the Rcs regulon (Table 4). These re- 
sults indicate that these target genes are indeed directly regulated by Rcs system. Of particular interest are several membrane proteins including EAM_0255 and EAM_2938 (and EAM_02937) (Table 1). Their differential expression pattern in vitro indicates that their regulation mechanism may differ. Under in vivo conditions, EAM_0255,EAM_2938 (2937), and ams genes were expressed at lower levels in the rcs mutants, whereas under in vitro conditions, EAM_2938 has shown similar expression as in vivo, the expression of EAM_0255 and other ams genes were expressed at higher levels in the $\operatorname{rcs} C$ mutant. Further analysis reveals that at least two (HrpL and RcsB) and three (RcsB, OmpR, and HrpL [low bit-score value]) binding sites are predicted for EAM_2938 and EAM_0255 genes, respectively (data not shown). This may explain why they had different expression patterns in the $\operatorname{rcs} C$ mutant in vitro. Interestingly, oxyR (EAM_0142) and osmB (EAM_1733) had exactly the same expression patterns as those of $E A M \_2938$ and $E A M \_0255$, respectively (Table 1). These results suggest the existence of a possible regulatory network and that the Rcs system may regulate other two-component systems such as EnvZ/OmpR and other regulatory genes such as $h r p S, h r p L, f l h D$, and $f l h C$. Another possible explanation may be related to the relative abundance of Rcs proteins. At transcription level, the expression of $r \operatorname{cs} A, \operatorname{rcs} C$, and $r \operatorname{cs} D$ is significantly up-regulated in pear fruits, which caused a drastic change in ratios of mRNA among different $r c s$ components. It is likely that the induction of $r \operatorname{cs} A, r c s C$, and $r c s D$ expression affects the phosphor-flow of the Rcs system. On the other hand, the expression of $r \operatorname{cs} B$ remains constant in different conditions, indicating that the ratio of nonphosphorylated RcsB and phosphorylated RcsB may determine what genes are induced or suppressed. It will be interesting to know exactly how EAM_2938 and EAM_0255 are regulated by different systems.

One challenging question that remains in our understanding of the Rcs signaling pathways is the one or more environmental signals for RcsC activation. It has been shown that $\mathrm{RcsC}$ responds to a wide range of conditions, including solid surface, osmotic stresses, temperature, and dessication (Clarke 2010). Auxiliary proteins such as RcsF, DjlA, DsbA, and IgaA have been reported to either activate or inhibit RcsC activity (Clarke et al. 2002; Dominguez-Bernal et al. 2004; Majdalani et al. 2002, 2005). The mechanisms for these proteins to activate or inhibit the Rcs system still remain unclear as well as whether environmental signals are directly or indirectly perceived by RcsC. However, the current consensus supports the hypothesis that perturbations in the peptidoglycan layer or common antigen structure may play a major role in activating the Rcs phosphorelay, resulting in remodeling of the cell surface (Castelli and Garcia Vescovi 2011; Clarke 2010). Based on current data, possible signals that may lead to perturbations in cell walls or cell membranes include one or more of the following: reactive oxygen species (ROS), hard surface (host contact), and osmotic stress. It has been reported that E. amylovora induces an oxidative burst during infection (Venisse et al. 2001, 2003), and virulence factors such as amylovoran, DspF, HrpN, and siderophores could either protect bacteria from oxidative stress or make the pathogen more tolerant to high levels of hydrogen peroxide (Venisse et al. 2003). OxyR, the hydrogen peroxide-inducible gene activator (Christman et al. 1989), is also positively controlled by the Rcs phosphorelay.

Based on findings in this study and previous reported data, a model for the Rcs phosphorelay in E. amylovora is herein proposed (Fig. 5). The RcsC, RcsD, and RcsB are proposed to form a complex through the ABL domain (Schmoe et al. 2011). Upon phosphorylation, RcsB interacts with RcsA to form either RcsA-RcsB heterodimer or RcsB-RcsB homodimer, which then binds to an $R \operatorname{cs} A B$ box to regulate gene expression (Pristovsek et al. 2003). During plant infection, plant signals (presumably ROS and host contact) are perceived directly or indirectly by $\mathrm{RcsC}$ sensor kinase, which then phosphorylates RcsB, leading to amylovoran production, remodeling of the cell surface, and disease. After activation, other regulatory systems, such as the envelope-stress two-component system CpxAR, which is a positive regulator of amylovoran production, may also be involved. Without RcsC, the signals can not be sensed and other phosphor-donors are sparse; therefore, there is no activation of the Rcs system and disease. In laboratory growth medium, no such host-related signals exist; RcsC may act as a phosphatase and dephosphorylate RcsB, but RcsB can be phosphorylated by other phospho-donors such as acetyl $\sim \mathrm{P}$, which remains at high levels when cells are grown in medium. The net flow of phosphoryl groups results in reduced phospho-RcsB, and thus, less amylovoran production. Without $\mathrm{RcsC}$, net phospho-RcsB or the ratio of phosphor-RcsB versus nonphosphorylated RcsB increases, resulting in overactivation of the Rcs system, and thus, more amylovoran production. Overactivation of the Rcs system may suppress other regulators such as OmpR and HrpSL, both suppressors of amylovoran production. In summary, the findings in this study provide the first global view of the Rcs regulon in E. amylovora. Future functional analyses of the downstream genes of the Rcs regulon, reconstruction of the gene regulatory network, and determination of the signals sensed by the Rcs system will provide an integrated understanding of the vital role of the Rcs phosphorelay system in $E$. amylovora during interactions with host plants, which are currently underway.

\section{MATERIALS AND METHODS}

\section{Bacterial stains and growth conditions.}

The wild-type strain Ea1189 of E. amylovora and its $r c s B$ and $r c s C$ mutants were used in this study (Zhao et al. 2009b). $\mathrm{LB}$ broth and MBMA minimal medium $\left(3 \mathrm{~g}\right.$ of $\mathrm{KH}_{2} \mathrm{PO}_{4}, 7 \mathrm{~g}$ of $\mathrm{K}_{2} \mathrm{HPO}_{4}, 1 \mathrm{~g}$ of $\left[\mathrm{NH}_{4}\right]_{2} \mathrm{SO}_{4}, 2 \mathrm{ml}$ of glycerol, $0.5 \mathrm{~g}$ of citric acid, $0.03 \mathrm{~g}$ of $\mathrm{MgSO}_{4}$ ) plus $1 \%$ sorbitol (Wang et al. 2009) are used routinely for culturing $E$. amylovora. For growing $r c s B$ and $r c s C$ mutants, $20 \mu \mathrm{g}$ of kanamycin per milliliter was added to the medium.

\section{RNA isolation.}

Bacterial strains were grown overnight in LB medium supplemented with or without antibiotic and were diluted in $5 \mathrm{ml}$ of MBMA medium at an optical density at $600 \mathrm{~nm}\left(\mathrm{OD}_{600}\right)$ of 0.005 . After $18 \mathrm{~h}$ of growth in MBMA medium at $28^{\circ} \mathrm{C}, 2 \mathrm{ml}$ of RNA protect reagent (Qiagen, Hilden, Germany) was added to $1 \mathrm{ml}$ of bacterial cultures (at $\mathrm{OD}_{600}$ of about 0.5 to 0.8 ) to stabilize RNA. For in vivo conditions, bacterial strains were grown overnight in LB media and bacterial cells were collected by centrifugation. The cells were resuspended in phosphate buffered saline, were adjusted to an $\mathrm{OD}_{600}$ of 0.2 to 0.3 , and were inoculated onto immature pear fruit surface after cutting the fruit in half. For $r c s$ mutants, multiple pear slices were inoculated and cells were then pooled in order to recover sufficient bacterial cells for RNA extraction. After incubation at $28^{\circ} \mathrm{C}$ for up to $18 \mathrm{~h}$ with high humidity, bacterial cells were collected by washing with a solution containing $2 \mathrm{ml}$ RNA protect reagent (Qiagen) and $1 \mathrm{ml}$ RNase-free water.

Cells were harvested by centrifugation for $10 \mathrm{~min}$ at $4,000 \times g$ and RNA was extracted using Qiagen bacterial RNA protect mini kit as recommended by the manufacturer (Qiagen). Oncolumn DNA digestion was performed using Qiagen DNase. RNA was quantified using Nano-Drop ND-100 spectrophotometer (NanoDrop Technologies; Wilmington, DE, U.S.A.) 
and RNA quality was checked using the Agilent 2100 Bioanalyzer (Agilent Technologies, Palo Alto, CA, U.S.A.).

\section{Microarray hybridization and data analysis.}

The 60 -mer E. amylovora microarray $(8 \times 15,000)$ was purchased from Agilent, as described previously (McNally et al. 2011). This oligonucleotide microarray was designed at the James Hutton Institute (formerly the Scottish Crop Research Institute) and was synthesized by Agilent Technologies. Each slide contains eight arrays, and each array has nearly 15,000 spots containing each probe in triplicate. The microarray design is available at ArrayExpress website (accessions: microarray \#A-MEXP-2000). All microarray data are available at the National Center for Biotechnology Information (NCBI) Gene Expression Omnibus database (accession number GSE30751). Two biological replicates for each mutant and WT samples were hybridized to two arrays and cross compared as two technical replicates.

Total RNA $(10 \mu \mathrm{g})$ from each sample were reverse-transcribed and were labeled by Alexa Fluor dye 555, using the FairPlay III microarray labeling kit (Stratagene, La Jolla, CA, U.S.A.) according to manufacturer's instructions, except that purification steps were done using the QIAquick PCR purification kit (Qiagen). Microarray hybridization was performed using $600 \mathrm{ng}$ of dye-labeled cDNA in the presence of a $2 \times$ hybridization buffer (Agilent Technologies) for $17 \mathrm{~h}$ at $65^{\circ} \mathrm{C}$ in an Agilent rotating oven (10 rpm). Microarray slides were then washed for $1 \mathrm{~min}$ in gene expression wash buffer 1 at room temperature and another $1 \mathrm{~min}$ in gene expression wash buffer 2 (Agilent Technologies) at $37^{\circ} \mathrm{C}$. Slides were scanned using an Axon 4000B array scanner at 5- $\mu$ m resolution. Photomultiplier voltages were automatically adjusted using the Genepix Pro 6.0 software acquisition system to obtain maximal signal intensities with $<0.02 \%$ probe saturation. The resulting 16-bit images were processed using the GenePix Pro 6.0 image analysis software (vs. 6.0.1.26). Raw data were logarithmically transformed and normalized using the glowess method by $\mathrm{R}$ software (R.2.2.1).

Statistical comparisons were performed using multiple testing procedures to evaluate statistical significance for differentially expressed genes. A modified $t$-test was computed to measure the significance associated with each differential expression value. A gene expression value was decided to be significantly different when the $P$ value was less than 0.05 (except when otherwise mentioned) and the expression ratio was $\geq 2.0$ or $\leq 0.5$. Gene functions were assigned using data from the NCBI database.

\section{qRT-PCR.}

To validate the microarray data, qRT-PCR for selected target genes was performed. Approximately $1 \mu \mathrm{g}$ of total RNA was reverse-transcribed in a $20-\mu$ reaction using SuperScript III reverse transcriptase (Invitrogen, Carlsbad, CA, U.S.A.), following the manufacturer's instructions. For each sample, negative reverse-transcription reaction was done to verify the absence of genomic DNA contamination in subsequent qRTPCR. Primers used for qRT-PCR in this study are listed in Supplementary Table S3. Primer sequences were designed using Primer3 software. BLAST searches were performed to confirm gene specificity and the absence of multilocus matching at the primer site. SYBR Green reactions were performed using the ABI 7300 System (Applied Biosystems, Foster City, CA, U.S.A.) in 96-well optical reaction plates. One microliter of cDNA ( $2 \mathrm{ng}$ per reaction) or water (no-template control) were used as template for qRT-PCR reactions with Fast SYBR Green PCR master mix (Applied Biosystems), with primers at $500 \mathrm{nM}$ final concentration. Primer pairs $16 \mathrm{~S} 3$ and $16 \mathrm{~S} 4$,
amsG1 and amsG2, amsC1 and amsC2, amsD1 and amsD2, rcsA1 and $\operatorname{rcs} A 2, \operatorname{rcsB} 1$ and $r \operatorname{csB} 2, \operatorname{rcs} C 1$ and $\operatorname{rcs} C 2, \operatorname{rcsD} 1$ and $\mathrm{rcsD} 2$, dspE1 and dspE2 and hrpN1 and hrpN2 were used to detect the expression of $r r s A$, ams $G$, ams $C$, ams D, $r c s A$, $r c s B, r c s C, d s p E$, and $h r p N$ genes, respectively. qRT-PCR amplifications were carried out at $50^{\circ} \mathrm{C}$ for $2 \mathrm{~min}, 95^{\circ} \mathrm{C}$ for 10 min, followed by 40 cycles of $95^{\circ} \mathrm{C}$ for $15 \mathrm{~s}$ and $60^{\circ} \mathrm{C}$ for 1 min, and a final dissociation curve analysis step from $65^{\circ} \mathrm{C}$ to $95^{\circ} \mathrm{C}$. Technical replicate experiments were performed for each biological triplicate sample. Amplification specificity for each reaction was confirmed by the dissociation curve analysis. Determined cycle threshold $(\mathrm{Ct})$ values were then exploited for further analysis.

Gene expression levels were analyzed using the relative quantification $(\Delta \Delta \mathrm{Ct})$ method. A $16 \mathrm{~S}$ rDNA $(r r s A)$ gene was used as an endogenous control. A relative quantification (RQ) value was calculated for each gene with the control group as a reference. A $P$ value was computed using a moderated $t$-test to measure the significance associated with each RQ value. Variations were considered statistically significant when the $P$ value was $<0.05$. RQ values for $r \operatorname{cs} B$ and $r c s C$ mutants were then normalized to those of WT or control medium.

\section{Hidden Markov prediction of ResAB box.}

To identify potential RcsB-regulated target genes in the genome of E. amylovora, a sequence training set containing 17 RcsB binding sites was compiled and aligned using ClustalX 2.0. The resulting alignment was used as input to construct a HMM with the software package of HMMer (Eddy 1998). The HMMer function hmmsearch was used to query test data sets and the target genome of E. amylovora ATCC 49946 (NCBI, NC_013971) (Sebaihia et al. 2010), with a bit-score classifier threshold of 13 . An optimal model was only applied to intergenic regions derived from the E. amylovora ATCC 49946 genome sequence (using ASAP software) to predict candidate RcsB-binding sites of potential target genes. Predicted target genes were compared with RcsBC-regulated genes identified in the microarray assay and some were verified using qRTPCR.

\section{ACKNOWLEDGMENTS}

We thank P. E. Hedley and L. Pritchard of the James Hutton Institute, Invergowrie, U.K. for helping design and for sharing the microarray. This project was supported by the Agriculture and Food Research Initiative Competitive Grants Program grant no. 2010-65110-20497 from the United States Department of Agriculture National Institute of Food and Agriculture (Y. Zhao) and the Scottish Government Rural and Environment Science and Analytical Services (RESAS) Division and the Potato Council (I. Toth).

\section{LITERATURE CITED}

Andresen, L., Koiv, V., Alamae, T., and Mae, A. 2007. The Rcs phosphorelay modulates the expression of plant cell wall degrading enzymes and virulence in Pectobacterium carotovorum ssp. carotovorum. FEMS (Fed. Eur. Microbiol. Soc.) Microbiol. Lett. 273:229-238.

Bellemann, P., and Geider, K. 1992. Localization of transposon insertions in pathogenicity mutants of Erwinia amylovora and their biochemical characterization. J. Gen. Microbiol. 138:931-940.

Bereswill, S., and Geider, K. 1997. Characterization of the $r c s B$ gene from Erwinia amylovora and its influence on exoploysaccharide synthesis and virulence of the fire blight pathogen. J. Bacteriol. 179:1354-1361.

Bernhard, F., Coplin, D. L., and Geider, K. 1993. A gene cluster for amylovoran synthesis in Erwinia amylovora: Characterization and relationship to cps genes in Erwinia stewartii. Mol. Gen. Genet. 239:158168.

Bernhard, F., Poetter, K., Geider, K., and Coplin, D. L. 1990. The $r \operatorname{cs} A$ gene from Erwinia amylovora: Identification, nucleotide sequence, and regulation of exopolysaccharide biosynthesis. Mol. Plant Microbe Interact. 3:29-437. 
Bugert, P., and Geider, K. 1995. Molecular analysis of the ams operon required for exopolysaccharide synthesis of Erwinia amylovora. Mol. Microbiol. 15:917-933.

Carlier, A. L., and von Bodman, S. B. 2006. The rcsA promoter of Pantoea stewartii subsp. stewartii features a low-level constitutive promoter and an EsaR quorum-sensing-regulated promoter. J. Bacteriol. 188:45814584

Castelli, M. E., and Garcia Vescovi, E. 2011. The Rcs signal transduction pathway is triggered by enterobacterial common antigen structure alterations in Serratia marcescens. J. Bacteriol. 193:63-74.

Christman, M. F., Storz, G., and Ames, B. N. 1989. OxyR, a positive regulator of hydrogen peroxide-inducible genes in Escherichia coli and Salmonella typhimurium, is homologous to a family of bacterial regulatory proteins. Proc. Natl. Acad. Sci. U.S.A. 86:3484-3488.

Clarke, D. J. 2010. The Rcs phosphorelay: More than just a two-component pathway. Future Microbiol. 5:1173-1184.

Clarke, D. J., Joyce, S. A., Toutain, C. M., Jacq, A., and Holland, I. B 2002. Genetic analysis of the RcsC sensor kinase from Escherichia coli K-12. J. Bacteriol. 184:1204-1208.

Cuthbertson, L., Mainprize, I. L., Naismith, J. H., and Whitefield, C. 2009. Pivotal roles of the outer memberane polysaccharide export and polysaccharide copolymerase protein families in export of extracellular polysaccharides in gram-negative bacteria. Microbiol. Mol. Biol. Rev. 73:155-177

Detweiler, C. S., Monack, D. M., Brodsky, I. E., Mathew, H., and Falkow, S. 2003. virK, somA and $r c s C$ are important for systemic Salmonella enterica serovar Typhimurium infection and cationic peptide resistance. Mol. Microbiol. 48:385-400.

Dominguez-Bernal, G., Pucciarelli, M. G., Ramos-Morales, F., GarciaQuintanilla, M., Cano, D. A., Casadesus, J., and Garcia-del Portillo, F. 2004. Repression of the RcsC-YojN-RcsB phosphorelay by the IgaA protein is a requisite for Salmonella virulence. Mol. Microbiol. 53:1437-1449.

Eddy, S. R. 1998. Profile hidden Markov models. Bioinformatics 14:755 763

Erickson, K. D., and Detweiler, C. S. 2006. The Rcs phosphorelay system is specific to enteric pathogens/commensals and activates ydeI, a gene important for persistent Salmonella infection of mice. Mol. Microbiol. 62:883-894.

Ferrières, L., and Clarke, D. J. 2003. The RcsC sensor kinase is required for normal biofilm formation in Escherichia coli K-12 and controls the expression of a regulon in response to growth on a solid surface. Mol. Microbiol. 50:1665-1682.

Francez-Charlot, A., Laugel, B., Van Gemert, A., Dubarry, N., Wiorowski, F., Castanie-Cornet, M. P., Gutierrez, C., and Cam, K. 2003. RcsCDB His-Asp phosphorelay system negatively regulates the flhDC operon in Escherichia coli. Mol. Microbiol. 49:823-832.

Fredericks, C. E., Shibata, S., Aizawa, S., Reimann, S. A., and Wolfe, A. J. 2006. Acetyl phosphate-sensitive regulation of flagellar biogenesis and capsular biosynthesis depends on the Rcs phosphorelay. Mol. Microbiol. 61:734-747.

Hagiwara, D., Sugiura, M., Oshima, T., Mori, H., Aiba, H., Yamashino, T., and Mizuno, T. 2003. Genome-wide analyses revealing a signaling network of the RcsC-YojN-RcsB phosphorelay system in Escherichia coli. J. Bacteriol. 185:5735-5746.

Hinchliffe, S. J., Howard, S. L., Huang, Y. H., Clarke, D. J., and Wren, B. W. 2008. The importance of the Res phosphorelay in the survival and pathogenesis of the enteropathogenic yersiniae. Microbiology 154:11171131.

Hoch, J. A., and Silhavy, T. J. 1995. Two-component Signal Transduction. ASM Press, Washington, D.C.

Huang, Y. H., Ferrieres, L., and Clarke, D. J. 2006. The role of the Rcs phosphorelay in Enterobacteriaceae. Res. Microbiol. 157:206-212.

Jayaratne, P., Keenleyside, W. J., MacLachlan, P. R., Dodgson, C., and Whitfield, C. 1993. Characterization of $r c s B$ and $r c s C$ from Escherichia coli $\mathrm{O} 9: \mathrm{K} 30: \mathrm{H} 12$ and examination of the role of the $r c s$ regulatory system in expression of group I capsular polysaccharides. J. Bacteriol. 175:5384-5394

Kato, A., Mitrophanov, A. Y., and Groisman, E. A. 2007. A connector of two-component regulatory systems promotes signal amplification and persistence of expression. Proc. Natl. Acad. Sci. U.S.A. 104:1206312068.

Kelm, O., Kiecker, C., Geider, K., and Bernhard, F. 1997. Interaction of the regulator proteins $\mathrm{RcsA}$ and $\mathrm{RcsB}$ with the promoter of the operon for amylovoran biosynthesis in Erwinia amylovora. Mol. Gen. Genet. 256:72-83.

Khan, M. A., Zhao, Y. F., and Korban, S. S. 2011. Molecular mechanism of pathogenesis and resistance to the bacterial pathogen Erwinia amylovora, causal agent of fire blight disease in Rosaceae. Plant Mol. Biol. Rep. Published online. DOI:10.1007/s11105-011-0334-1.
Koczan, J. M., McGrath, M. T., Zhao, Y. F., and Sundin, G. W. 2009. Contribution of Erwinia amylovora exopolysaccharides amylovoran and levan to biofilm formation: Implications in pathogenicity. Phytopathology 99:1237-1244.

Laubacher, M. E., and Ades, S. E. 2008. The Rcs phosphorelay is a cell envelope stress response activated by peptidoglycan stress and contributes to intrinsic antibiotic resistance. J. Bacteriol. 190:2065-2074.

Majdalani, N., and Gottesman, S. 2005. The Res phosphorelay: A complex signal transduction system. Annu. Rev. Microbiol. 59:379-405.

Majdalani, N., Hernandez, D., and Gottesman, S. 2002. Regulation and mode of action of the second small RNA activator of RpoS translation, RprA. Mol. Microbiol. 46:813-826.

Majdalani, N., Heck, M., Stout, V., and Gottesman, S. 2005. Role of RcsF in signaling to the Rcs phosphorelay pathway in Escherichia coli. J. Bacteriol. 187:6770-6778.

Mariscotti, J. F. and Portillo, F. G. 2009. Genome expression analysis revealing the modulation of the Salmonella Rcs regulon by the attenuator IgaA. J. Bacteriol. 191:1855-1867.

McNally, R., Toth, I., Cook, P., Pritchard, L., Hedley, P., Morris, J. A., Zhao, Y. F., and Sundin, G. W. 2011. Genetic characterization of the HrpL regulon of the fire blight pathogen Erwinia amylovora reveals novel virulence factors. Mol. Plant Pathol. DOI 10.1111/J.13643703.2011.00738.X

Nimtz, M., Mort, A., Domke, T., Wray, V., Zhang, Y., Qiu, F., Coplin, D., and Geider, K. 1996. Structure of amylovoran, the capsular exopolysaccharide from the fire blight pathogen Erwinia amylovora. Carbohydr. Res. 287:59-76.

Oshima, T., Aiba, H., Masuda, Y., Kanaya, S., Sugiura, M., Wanner, B. L., Mori, H., and Mizura, T. 2002. Transcriptome analysis of all two-component regulatory system mutants of Escherichia coli. Mol. Microbiol. 46:281-291.

Peleg, A., Shifrin, Y., Ilan, O., Nadler-Yona, C., Nov, S., Koby, S., Baruch, K., Altuvia, S., Elgrably-Weiss, M., Abe, C. M., Knutton, S., Saper, M. A., and Rosenshine, I. 2005. Identification of an Escherichia coli operon required for formation of the O-antigen capsule. J. Bacteriol. 187:5259-5266.

Pristovsek, P., K. Sengupta, F. Lohr, B. Schafer, M. W. von Trebra, H. Ruterjans and Bernhard, F. 2003. Structural analysis of the DNA-binding domain of the Erwinia amylovora $\mathrm{RcsB}$ protein and its interaction with the RcsAB box. J. Biol. Chem. 278:17752-17759.

Schmoe, K., Rogov, V. V., Yu, N., Lohr, F., Guntert, P., Bernhard, F., and Dotsch, V. 2011. Structural insights into Rcs phosphotransfer: The newly identified RcsD-ABL domain enhances interaction with the response regulator RcsB. Structure 19:577-587.

Sebaihia, M., Bocsanczy, A. M., Biehl, B. S., Quail, M. A., Perna, N. T., Glasner, J. D., DeClerck, G. A., Cartinhour, S., Schneider, D. J., Bentley, S. D., Parkhill, J., and Beer, S.V. 2010. Complete genome sequence of the plant pathogen Erwinia amylovora strain ATCC 49946. J. Bacteriol. 192:2020-2021

Sjulin, T. M., and Beer, S. V. 1978. Mechanism of wilt induction by amylovoran in Cotoneaster shoots and its relation to wilting of shoots infected by Erwinia amylovora. Phytopathology 68:89-94.

Takeda, S., Fujisawa, Y., Matsubara, M., Aiba, H., and Mizuno, T. 2001. A novel feature of the multistep phosphorelay in Escherichia coli: A revised model of the $\mathrm{RcsC}-->$ YojN --> RcsB signalling pathway implicated in capsular synthesis and swarming behaviour. Mol Microbiol. 40:440-450.

Vanneste, J. L. 2000. Fire Blight: The Disease and Its causative Agent, Erwinia amylovora. CABI Publishing, New York.

Venisse, J.-S., Gullner, G., and Brisset, M.-N. 2001. Evidence for the involvement of an oxidative stress in the initiation of infection of pear by Erwinia amylovora. Plant Physiol. 125:2164-2172.

Venisse, J.-S., Barny, M.-A., Paulin, J.-P., and Brisset, M.-N. 2003. Involvement of three pathogenicity factors of Erwinia amylovora in the oxidative stress associated with compatible interaction in pear. FEBS Lett. 537:198-202.

Wang, D., Korban, S. S., and Zhao, Y. F. 2009. The Rcs phosphorelay system is essential for pathogenicity in Erwinia amylovora. Mol. Plant Pathol. 10:277-290.

Wang, D., Korban, S.S., Pusey, L., and Zhao, Y. F. 2011. Characterization of the RcsC sensor kinase from Erwinia amylovora and other enterobacteria. Phytopathology 101:710-117.

Wang, Q., Zhao, Y., McClelland, M., and Harshey, R. M. 2007. The RcsCDB signaling system and swarming motility in Salmonella enterica serovar typhimurium: Dual regulation of flagellar and SPI-2 virulence genes. J. Bacteriol. 189:8447-8457.

Wehland, M., and Bernhard, F. 2000. The RcsAB box. Characterization of a new operator essential for the regulation of exopolysaccharide biosynthesis in enteric bacteria. J. Bio. Chem. 275:7013-7020.

Wehland, M., Kiecker, C., Coplin, D. L., Kelm, O., Saenger, W., and 
Bernhard, F. 1999. Identification of an RcsA/RcsB recognition motif in the promoters of exopolysaccharide biosynthetic operons from Erwinia amylovora and Pantoea stewartii subspecies stewartii. J. Biol. Chem. 274:3300-3307.

Zhao, Y. F., Blumer, S. E., and Sundin, G. W. 2005. Identification of Erwinia amylovora genes induced during infection of immature pear tissue. J. Bacteriol. 187:8088-8103.

Zhao, Y. F., He, S. Y., and Sundin, G. W. 2006. The Erwinia amylovora avrRpt $_{E A}$ gene contributes to virulence on pear and AvrRpt $2_{\mathrm{EA}}$ is recognized by Arabidopsis RPS2 when expressed in Pseudomonas syringae. Mol. Plant-Microbe Interact. 19:644-654.

Zhao, Y. F., and Qi, M. S. 2011. Comparative genomics of Erwinia amylovora and related Erwinia species-What do we learn? Genes 2:627-639.

Zhao, Y. F., Sundin, G. W., and Wang, D. 2009a. Construction and analysis of pathogenicity island deletion mutants of Erwinia amylovora. Can. J. Microbiol. 55:457-464.
Zhao, Y. F., Wang, D., Nakka, S., Sundin, G. W., and Korban, S. S. 2009b. Systems level analysis of two-component signal transduction systems in Erwinia amylovora: Role in virulence, regulation of amylovoran biosynthesis and swarming motility. BMC Genomics 10:245.

\section{AUTHOR-RECOMMENDED INTERNET RESOURCES}

ArrayExpress database: www.ebi.ac.uk/arrayexpress

HMMer software: hmmer.janelia.org

National Center for Biotechnology Information (NCBI) website: www.ncbi.nlm.nih.gov

NCBI Gene Expression Omnibus database: www.ncbi.nlm.nih.gov/geo

Primer3 database: frodo.wi.mit.edu/primer3

University of Wisconsin-Madison Genome Evolution Laboratory's ASAP software: asap.ahabs.wisc.edu/software/asap 